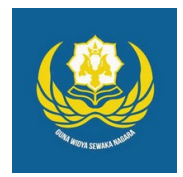

Jurnal Analogi Hukum

Journal Homepage: https://ejournal.warmadewa.ac.id/index.php/analogihukum

\title{
Penerapan Sanksi Pidana Terhadap Pelaku Tindak Pidana yang Mengedarkan Kosmetika Tanpa Izin Edar (Study Kasus Pengadilan Negeri Gianyar Nomor Pekara 132/Pid.Sus/2018 PN Gin)
}

\author{
I Komang Triana Diantara*, Ida Ayu Putu Widiati dan Ni Made Sukaryati Karma
}

Fakultas Hukum, Universitas Warmadewa, Denpasar-Bali, Indonesia

*triana.diantara@gmail.com

How To Cite:

Diantara, I. K. T., Widiati, I. A. P., \& Karma, N. M. S. (2020). Penerapan Sanksi Pidana Terhadap Pelaku Tindak Pidana yang Mengedarkan Kosmetika Tanpa Izin Edar (Study Kasus Pengadilan Negeri Gianyar Nomor Pekara 132/Pid.Sus/2018 PN Gin). Jurnal Analogi Hukum. 2(2). 264-269. Doi: https://doi.org/10.22225/ah.2.2.1931.264-269

\begin{abstract}
Criminal Sanctions Against Criminal Acts Circulating Cosmetics Pharmacy Supplies Without Circular Permission, this study aims because of the increasingly widespread circulation of cosmetics that do not have a marketing authorization but are still widely sought after and used by the public. This research has two problem formulations to be discussed namely, first, how is the regulation of cosmetics distribution in the market which does not have a marketing authorization? And the second is how criminal sanctions against the perpetrators who circulate cosmetics that do not have marketing authorization? This research uses normative legal methods. Based on the results of this study that the author examines through analyzing cases using the Gianyar District Court Decision Case Number 132 / Pid.Sus / 2018 / PN Gin. This study uses a Per-Invitation approach by examining all the laws relating to this case, Conceptual by combining expert opinions so that the author's legal argumentation and case approach is to use a court decision. The results of this study indicate that the role of the health service of the Republic of Indonesia is more assertive in providing health standards and benefits for cosmetics producers so that there are no more fraudulent and irresponsible cosmetic manufacturers using hazardous materials in the manufacture of cosmetics. The imposition of criminal sanctions against criminal acts circulates cosmetics pharmaceutical preparations without marketing authorization as regulated in Law Number 36 Year 2009 concerning Health as regulated in articles 197-201. In the case raised in this study the Panel of Judges considered Article 197 with a maximum imprisonment of 15 (fifteen) years and a maximum fine of 1,500,000,000 (one billion five hundred million rupiah). But the defendant here was only sentenced to imprisonment for 8 (eight) months and a fine of Rp 2,000,000 (two million rupiah) provided that if the fine was not paid it would be replaced with a 2 months confinement sentence. The role of the Republic of Indonesia health service is more assertive in providing health standards and benefits so that there are no more fraudulent and irresponsible cosmetic manufacturers.
\end{abstract}

Keywords: Criminal Sanctions, Pharmaceutical Cosmetics, Without Permission

\begin{abstract}
Abstrak-Sanksi pidana terhadap tindak pidana mengedarkan sediaan farmasi kosmetika tanpa izin edar, penelitian ini bertujuan karena semakin maraknya peredaran kosmetika yang tidak mempunyai izin edar namun tetap banyak diminati dan digunakan oleh masyarakat. Penelitian ini memiliki dua rumusan masalah yang akan dibahas yaitu, pertama bagaimanakah pengaturan mengedarkan kosmetika di pasaran yang tidak memiliki izin edar? Dan yang kedua bagaimanakah sanksi pidana terhadap para pelaku yang mengedarkan kosmetika yang tidak memiliki izin edar? Penelitian ini menggunakan metode hukum normatif. Berdasarkan dari hasil penelitian ini bahwa penulis mengkaji melalui analisis kasus menggunakan Putusan Pengadilan Negeri Gianyar Nomor Perkara 132/Pid.Sus/2018/PN Gin. Penelitian ini menggunakan pendekatan Perundang -undangan dengan menelaah semua undang-undang yang berhubungan dengan kasus ini, Konseptual yaitu dengan menggabungkan pendapat para ahli sehingga menjadi argumentasi hukum penulis, dan pendekatan kasus yaitu dengan menggunakan putusan pengadilan. Hasil penelitian ini menunjukan bahwa peran dinas kesehatan Republik Indonesia lebih tegas dalam memberikan standard kesehatan dan kemanfaatan bagi produsen-produsen kosmetik agar tidak lagi ada produsen kosmetik yang curang dan tidak bertanggung jawab
\end{abstract}

Jurnal Analogi Hukum, Volume 2, Nomor 2, 2020. CC-BY-SA 4.o License 
dengan menggunakan bahan berbahaya dalam pembuatan kosmetiknya. Pengenaan sanksi pidana terhadap tindak pidana mengedarkan sediaan farmasi kosmetika yang tidak memiliki izin edar sebagaimana diatur dalam UU 36 Tahun 2009 Tentang Kesehatan diatur dalam Pasal 197-201. Dalam kasus penelitian ini Majelis Hakim mempertimbangkan dengan Pasal 197 dengan hukuman penjara maksimal 15 (lima belas) tahun dan denda maksimal 1.500.000.000 (satu milyar lima ratus juta rupiah). Tetapi terdakwa disini hanya dijatuhkan pidana penjara selama 8 (delapan) bulan dan denda sejumlah Rp 2.000.000,- (dua juta rupiah) dengan ketentuan apabila denda tersebut tidak dibayar maka akan diganti dengan pidana kurungan selama 2 (dua) bulan. Peran dinas kesehatan republik Indonesia lebih tegas dalam memberikan standar kesehatan dan kemanfaatan agar tidak lagi ada produsen kosmetik curang dan tidak bertanggung jawab.

Kata Kunci: Sanksi Pidana, Farmasi Kosmetika, Tanpa Izin.

\section{Pendahuluan}

Cita-cita bangsa Indonesia merupakan tujuan nasional bangsa Indonesia yang sudah tercantum jelas dalam pembukaan UUD 1945. Agar mencapai tujuan nasional dapat diselenggarakan dengan pembangunan terpadu dan menyeluruh termasuk pembangunan di bidang kesehatan (Hendrik, 2011).

Sebagaimana dimaksud dalam Pancasila dan Pembukaan UUD 1945 kesehatan adalah kesejahteraan dan hak asasi manusia yang salah satunya patut diwujudkan. Terdapat 2 aspek dari kesehatan yaitu, yang pertama aspek upaya kesehatan dapat dibagi menjadi pemeliharaan kesehatan individu dan pemeliharaan kesehatan masyarakat, kedua aspek sumber daya kesehatan yang terdiri atas prasarana kesehatan (Supriadi, 2001).

Kosmetik merupakan salah satu kejahatan hukum yang sering terjadi di masyarakat yaitu dalam mengedarkan sediaan farmasi kosmetik tanpa izin edar. Kosmetik mempunyai pengaruh besar dalam penampilan seseorang maka tidak heran kebutuhan kosmetik terus meningkat. Kosmetik yang ingin diedarkan atau diproduksi dapat memenuhi syarat seperti kesehatan dan keselamatan yang ditetapkan oleh Menteri Kesehatan yang baik (CKPB) dan hal tersebut tercantum pada Surat Keputusan Menteri Kesehatan RI No. 965/MenKes/SK/XI/1992.

Cara memproduksi kosmetik yang benar yaitu dengan melakukan pengawasan secara menyeluruh yaitu pada pengendalian mutu dan aspek produksi agar hasil yang diproduksi dapat sesuai dengan syarat - syarat bermutu, bermanfaat dan aman bagi yang pemakainya.

Banyak kosmetik yang beredar bebas di pasaran. Keinginan perempuan yang selalu ingin terlihat cantik banyak dimanfatkan oleh pelaku usaha yang tidak bertanggung jawab dengan berbagai bahan kimia yang terdapat dalam kosmetik. Masih banyak kosmetik yang beredar tanpa adanya izin edar atau tidak terdaftar BPOM. Terdapat ketentuan pidana untuk menghindari pengadaan, penyalahgunaan dalam menggunakan alat kesehatan atau sediaan farmasi sehingga membahayakan masyarakat dari pihak yang tidak memiliki rasa tanggungjawab, mengedarkan kosmetik tanpa izin edar yang diatur dengan ketentuan pidana pasal 106 dan pasal 196 dalam Undang-Undang No. 36 Tahun 2009 tentang Kesehatan. Pada penelitian (Rusmini, 2016), mengemukakan tindak pidana mengedarkan sediaan farmasi tanpa izin edar yang diatur dalam UU No. 36 Tahun 2009 Tentang Kesehatan berfungsi sebagai mengoptimalisasi hukum pidana sebagai sarana dalam upaya pencegah kejahatan. Penerapan Undang-Undang ini diharapkan dapat menjerat para pelaku tindak pidana mengedarkan sediaan farmasi tanpa izin edar.Serta upaya yang dapat dilakukan dalam penanganan tindak pidana ini dilakukan dengan kebijakan penal dan non penal. Pada penelitian lainnya (Qira'a, Pratimaratri, \& Saini, 2019), mengungkapkan bahwa Penerapan tindak pidana dengan sengaja mensirkulasikan sediaan farmasi tanpa izin distribusi, yang dikenakan pada terdakwa sesuai dengan fakta hukum baik kesaksian saksi, pernyataan terdakwa, tuntutan dan tuntutan dengan ancaman sanksi pidana dan hukuman pidana dalam Pasal 197 UU No. 36 tahun 2009 tentang Kesehatan. Kedua, Pertimbangan Hakim dalam tindakan kriminal dengan sengaja mengedarkan sediaan farmasi yang tidak memiliki izin distribusi ini dengan benar berdasarkan pertimbangan sebagaimana dinyatakan dalam keputusan.

Adapun kasus yang terkait dengan tindak pidana Kesehatan yang diangkat oleh penulis adalah tindak pidana Kesehatan "Mengedarkan Kosmetika Tanpa Izin Edar" oleh terdakwa Ni Ketut Erawati. Yang ditangkap oleh BPOM dan barang bukti berupa Krim Pemutih Wajah, Krim Malam, Krim Pagi disita.

Berdasarkan uraian diatas, penulis merumuskan 2 (dua) permasalahan yaitu Bagaimana pengaturan mengedarkan kosmetika di pasaran yang tidak memiliki izin edar dan sanksi pidana terhadap para pelaku yang mengedarkan kosmetika yang tidak memiliki izin edar. Adapun tujuan dari penelitian ini untuk mengidentifikasi dan menjelaskan agar masyarakat awam tau pengaturan mengedarkan 
kosmetika yang boleh beredar di pasaran menurut hukum positif di indonesia dan untuk menjelaskan sanksi pidana terhadap para penjual yang tidak mempunyai izin mengedarkan kosmetika dan tidak memenuhi standar kesehatan BPOM.

\section{Metode}

Penelitian hukum normatif digunakan dalam penelitian ini menganalisis kepustakaan berdasarkan bahan hukum yang digunakan, baik primer maupun sekunder. Sedangkan pendekatan masalah yang digunakan dalam penelitian ini yaitu pendekatan perundangundangan, pendekatan kasus, dan pendekatan konseptual.

Dalam membahas Sanksi Pidana Terhadap Tindak Pidana Pengedaran Kosmetika Tanpa Izin Edar menggunakan sumber bahan hukum. Sumber bahan Hukum yang digunakan penulis adalah sebagai berikut:

\section{Bahan Hukum Primer}

Bahan hukum mempunyai kekuatan mengikat dalam penelitian ini meliputi, UUD Negara Republik Indonesia 1945, UndangUndang Republik Indonesia 36 Tahun 2009 Tentang Kesehatan Undang-Undang 30 Tahun 2014 Tentang administrasi Pemerintahan, Peraturan Presiden Nomor 80 Tahun 2017 Tentang Badan Pemeriksa Obat dan Makanan, dan berbagai instrument hukum yang relavan terkait Sanksi Pidana Terhadap Tindak Pidana Mengedarkan Sediaan Farmasi Tanpa Izin Edar.

\section{Bahan Hukum Sekunder}

Bahan hukum yang menjelaskan tentang bahan hukum primer yang didapat melalui pengkajian kepustakaan, meliputi buku-buku, jurnal-jurnal hukum, dan artikel yang berhubungan dengan Sanksi Pidana Terhadap Tindak Pidana Pengedaran Kosmetika Tanpa Izin Edar.

Pada penelitian ini untuk memperoleh bahan-bahan hukum primer, sekunder digunakan dengan mengumpulan bahan hukum lalu dikelompokan dan didokumentasikan, dicatat, dikutip, diringkas, diulas sesuai kebutuhan dengan pendekatan kualitatif.

Menganalisis penelitian ini menggunakan teknik bersifat sistematis dengan disajikan secara deskriptif analitis, yaitu dengan mendiskripsikan bahan hukum terlebih dahulu secara sistematis kemudian menganalisa melalui teknik analisis dengan teknik tafsiran dan menggunakan argumentasi yang bertumpu pada logika hukum dengan deduktif induktif.

\section{Hasil dan Pembahasan}

\section{Pengaturan Mengedarkan Kosmetika Di Pasaran yang Tidak Memiliki Izin Edar}

Tranggono berpendapat bahwa, kosmetika merupakan bahan-bahan yang digunakan untuk memberikan dampak kecantikan dan kesehatan bagi tubuh (Tranggono, 2007) Obat, bahan obat, obat tradisional, dan kosmetika tergolong sedian farmasi dan hal ini tertuang dalam Pasal 1 (4) Undang-undang 36 Tahun 2009 Tentang Kesehatan.

Di dalam dunia kosmetika berbagai jenis merk dengan harga yang lebih murah akan membuat konsumen lebih cenderung untuk membeli kosmetik tersebut. Ketidaktahuan dari bahaya penggunaan kosmetika tanpa ijin tersebut akan membuat produk tersebut tetap laku dipasaran, walapun konsumen tidak mengetahui efek samping dari kosmetika tanpa ijin tersebut yang penggunaannya dalam jangka panjang dapat menyebabkan terjadinya berbagai jenis penyakit kulit. Masih maraknya bahaya dalam penggunaan kosmetik tanpa ijin tersebut dipasaran. Hilang dan kuranganya perhatian konsumen dalam mengamati ataupun meneliti kemasan produk baik kandungan maupun label perusahaan dalam membeli ataupun menggunakan produk tersebut sehingga produk tersebut cenderung laku dipasaran. Selain itu untuk kalangan yang menetapkan harga sebagai salah satu pertimbangan, harga yang murah merupakan salah satu daya tarik.

Vos berpendapat bahwa, tindak pidana merupakan salah satu perilaku manusia diancam pidana oleh peraturan-peraturan undang-undang, jadi suatu kelakuan pada umumnya dilarang dengan ancaman pidana (Andrisman, 2009).

Moeljatno berpendapat, Tindak pidana merupakan suatu pengertian yuridis dalam memberikan pengertian atau definisi dalam istilah hukum, pidana adalah suatu istilah yuridis yang memiliki arti khusus sebagai terjemahan dari bahasa Belanda "straf" yang diartikan sebagai "hukuman" (Moeljatno, 1987).

Jadi, menurut penulis tindak pidana merupakan perbuatan yang dilarang oleh undang-undang dimana larangan ini disertai dengan sanksi yang berupa pidana tertentu. Jika sediaan farmasi tersebut tidak memiliki izin dari 
Badan Pengawas Obat dan Makanan maka sediaan farmasi tersebut tidak boleh diedarkan dan itu artinya ada sanksi bagi pelaku usaha yang sengaja mengedarkan sediaan farmasi yang tidak memiliki izin edar. Unsur tindak pidana dibedakan dari dua sudut pandang yakni pandangan monistis dan pandangan dualistis.

\section{Sanksi Pidana Terhadap Para Pelaku yang Mengedarkan Kosmetika yang Tidak Memiliki Izin Edar}

Pertimbangan hakim adalah suatu aspek yang penting untuk menentukan nilai dari suatu keputusan hakim, yang mengandung kepastian hukum dan keadilan (ex aequo et bono). Selain itu memiliki manfaat bagi pihak yang bersangkutan sehingga pertimbangan hakim tersebut harus dilakuan dengan teliti, cermat dan baik.

Dalam memeriksa suatu perkara hakim sangat memerlukan bukti, hasil pembuktian tersebut akan dimanfaatkan untuk pertimbangan dalam memutuskan suatu perkara. Tahap yang terpenting dalam sebuah persidangan yaitu pembuktian. Adapun tujuan dari pembuktian untuk mendapatkan kepastian bahwa peristiwa atau fakta yang dilaporkan itu benar adanya, agar memperoleh putusan hakim yang adil dan benar. Hakim sebelum menjatuhkan putusan tidak boleh mengetahui fakta atau peristiwa itu benar adanya, harus dibuktikan bahwa memang benar terjadi sehingga terlihat adanya hubungan antara para pihak dan hukum diantara mereka.

Kekuasaan hakim yakni mereka yang berkuasa atau bisa dibilang merdeka artinya mereka yang tidak terikat oleh pengaruh atau kekuasaan pemerintah. Berhubungan dengan itu, setiap hakim memiliki kekuasaan untuk menentukan sebuah keputusan yang dibuat tanpa keikutsertaan orang lain. Hal tersebut yang mendasari adanya sesuatu kekuasaan yang bebas bagi hakim. Hakim dalam melakukan tugasnya dituntut mempunyai ketegasan, berani dalam menegakkan hukum tanpa pandang bulu dan tidak pamrih, hal ini terdapat dalam Pasal 4 ayat (1) UU No. 48 Tahun 2009 tentang Kekuasaan Kehakiman.

Andi Hamzah menjelaskan, hakim dalam menjatuhkan hukuman pidana haruskan menjamin tegaknya kebenaran, kepastian hukum dan keadilan untuk seseorang (Hamzah, 1986). Terdapat dua faktor bagi hakim yang wajib dilihat dalam menjatuhkan hukuman, yaitu ada hal yang memberatkan dan meringankan (Waluyo, 2000). Adapun faktor yang dapat meringankan adalah, terdakwa bersikap sopan dan santun, masih dalam rentang remaja dan mau mengakui perbuatannya. Sedangkan faktor yang dapat memberatkan adalah terdakwa tidak mau mengakui perbuatannya, memberi keterangan palsu, membuat rugi Negara, mengganggu kenyamanan masyarakat, dan lain sebagainya.

Hakim memiliki jenis pidana yang seharusnya didakwakan untuk terdakwa yaitu pidana pokok dan pidana tambahan yang terdapat dalam Pasal 10 KUHP. Tetapi di dalam penerapan sanksi pidana diatas, terdapat beberapa pilihan lain yang bisa digunakan sesuai dengan perbuatan terdakwa baik berat maupun ringannya perbuatan tersebut yakni pemidanaan bersyarat, dimana terdapat dalam Pasal 14a sampai dengan Pasal 14f KUHP. Adapun cara untuk pemidanaan tersebut dimaksud apabila ia melihat lebih bermanfaat untuk masyarakat.

Sanksi Pidana adalah salah satu hukuman sebab dan akibat, sebab adalah kasus yang diperbuat dan akibat adalah hukuman yang diterima. Seseorang yang terkena akibat maka mendapatkan hukuman masuk penjara, ataupun terkena hukuman lain dari pihak yang berwajib. Salah satu jenis sanksi yang bersifat duka yang diberikan kepada pelaku tindak pidana yang dapat membahayakan dan merusak kepentingan hukum disebut sanksi pidana. Pada dasarnya sanksi pidana merupakan salah satu penjamin dalam mengubah perilaku dan pola pikir bagi pelaku kejahatan tersebut, namun bagi beberapa orang sanksi pidana tersebut dibuat untuk ancaman dari kebebasan manusia tersebut. Sanksi pidana yang didakwakan kepada pelaku kejahatan dapat dibagi menjadi dua macam yaitu pidana pokok dan pidana tambahan.

Sesuai dengan kasus yang penulis tuangkan yaitu Putusan Pengadilan Negeri Gianyar Nomor Perkara 132/Pid.Sus/2018/PN Gin. bahwa sudah memenuhi unsur-unsur di ketentuan Undang-undang Nomor 36 Tahun 2009 Tentang Kesehatan. Penulis berpendapat, memang sudah sangat pantas mendapat hukuman sesuai yang terdapat di dalam amar putusan karena perbuatan terdakwa sangat merugikan masyarakat luas baik dari segi ekonomi, sosial, maupun budaya karena yang seperti tertuang di dalam Undang-undang Dasar Negara Republik Inonesia Tahun 1945 Pasal 28 $h$ ayat (1).

\section{Simpulan}

Pengaturan Tindak Pidana Mengedarkan Sediaan Farmasi Kosmetika Tanpa Izin Edar sudah jelas diatur di dalam Pasal 196 dan 197 
Undang-undang Nomor 36 Tahun 2009 tentang kesehatan. Siapapun yang dengan sengaja memproduksi sediaan farmasi atau alat kesehatan yang tidak sesuai dengan standar kesehatan atau keamanan dipidana penjara paling lama 10 (sepuluh) tahun dan siapapun yang dengan sengaja mengedarkan sediaan farmasi atau alat kesehatan yang tidak memiliki izin edar dipidana penjara paling lama 15 (lima belas) tahun dengan denda paling tinggi $\mathrm{Rp}$. 1.500.000.000,00 (satu miliar lima ratus juta rupiah). Pengedaran kosmetik tanpa izin edar ini pun sangat berbahaya bagi penggunanya karena kosmetik yang tidak memiliki izin edar artinya kosmetik ini sebenarnya tidak layak dijual di pasaran karena bahan-bahan pembuatan yang berbahaya yang tidak sesuai standar kesehatan yang dikeluarkan oleh Kementerian Kesehatan Republik Indonesia yang memiliki efek samping sangat berbahaya bagi kesehatan masyarakat jika digunakan dalam jangka waktu yang panjang.

Pengenaan Sanksi Pidana Terhadap Tindak Pidana Mengedarkan Sediaan Farmasi Kosmetika Tanpa Izin Edar Pasal 197 jo. Pasal 106 ayat (1) Undang-undang No 36 Tahun 2009 Tentang Kesehatan oleh Terdakwa NI KETUT ERAWATI adalah pidana penjara selama 8 (delapan) bulan dengan denda sebesar $\mathrm{Rp}$. 2.000.000,- (dua juta rupiah) dengan ketentuan apabila denda tersebut tidak dibayar diganti dengan pidana kururan selama 2 (dua) bulan.

Peran Dinas Kesehatan Republik Indonesia lebih tegas dalam memberikan standar kesehatan dan kemanfaatan bagi produsenprodusen kosmetik agar tidak lagi ada produsen kosmetik curang dan tidak bertanggungjawab dengan menggunakan bahan berbahaya dalam pembuatan kosmetiknya. Selain itu diharapkan untuk Dinas Kesehatan Republik Indonesia melalui kantor di daerah-daerah dapat memberikan sosialisasi secara terbuka kepada para generasi muda untuk tetap waspada dan peduli terhadap kesehatan dengan mulai memilah dan memilih kosmetik yang digunakan. Selain itu peranan Badan Pengawas Obat dan Makanan juga diharpakan selalu tepat waktu dan secara rutin mengadakan sidak untuk gerai-gerai kosmetik yang ada di daerah-daerah terutama di daerah Bali ini. Petugas dari BPOM pun juga dituntut untuk lebih tegas dalam menindaklanjuti masalah ini agar tidak ada lagi masyarakat yang merasa dirugikan oleh kasus ini. Selain itu BPOM juga secara berkala mengupdate informasi-informasi merek-merek dan jenis-jenis kosmetik yang terdaftar ataupun yang berbahaya. mencari informasi soal kosmetik yang dijual dipasaran sehingga masyarakat lebih pintar dalam memilih dan memilah kosmetik yang digunakan dan agar masyarakat mengetahui betapa bahayanya efek samping dari penggunaan kosmetik yang tidak memiliki izin edar tersebut karena kosmetik tersebut berbahan dasar bahan-bahan yang berbahaya bagi kesehatan.

\section{Daftar Pustaka}

Andrisman, T. (2009). Asas-asas dan Aturan Dasar Umum Hukum Pidana di Indonesia. Lampung: Universitas Lampung. Retrieved from https:// books.google.co.id/books/about/ Hukum_pidana.html? id $=$ A4SoZwEACAAJ\&redir_esc $=y$

Hamzah, A. (1986). Sistem Pidana dan Pemidanaan Indonesiadari Retrubusi ke Reformasi. Jakarta. Retrieved from Pradnya Paramita

Hendrik. (2011). Etika dan Hukum Kesehatan. Jakarta: Buku Kedokteran EGC. Retrieved from https:// kink.onesearch.id/Record/ IOS5808.slims-463/Details

Moeljatno. (1987). Asas-Asas Hukum Pidana. Jakarta: Bina Aksara.

Qira'a, H., Pratimaratri, U., \& Saini, Y. (2019). Penerapan Pidana Terhadap Tindak Pidana Yang Mengedarkan Sediaan Farmasi Berupa Obat Tanpa Izin Edar (Studi Perkara No: 360/Pid.Sus/2012/ PN.Ta). Abstract of Undergraduate Research, Faculty of Law, Bung Hatta University, 10(1), 1-9. Retrieved from http://www.ejurnal.bunghatta.ac.id/ index.php? journal $=\mathrm{JFH} \&$ page $=$ article\&op $=$ view $\&$ path $\% 5 B \% 5 \mathrm{D}=14338$

Rusmini, A. (2016). Tindak Pidana Pengedaran Dan Penyalahgunaan Obat Farmasi Tanpa Izin Edar Menurut UndangUndang Nomor 36 Tahun 2009 Tentang Kesehatan. Al-'Adl, 8(3), 23-44. Retrieved from https://media.neliti.com/ media/publications/225052-tindakpidana-pengedaran-dan-penyalahgunaf4aa237.pdf

Supriadi, W. C. (2001). Hukum Kedokteran. Jakarta: Mandar Maju. Retrieved from https://catalogue.nla.gov.au/ Record/1520645

Bagi masyarakat dituntut untuk lebih mau 
Tranggono. (2007). Buku Pegangan Ilmu Pengetahuan Kosmetik. Jakarta: PT. Gramedia Pustaka Utama. Retrieved from https://books.google.co.id/books? $\mathrm{id}=\mathrm{Zg} 5 \mathrm{hDwAAQBAJ} \&$ printsec $=$ frontc over\&hl=id\&source $=$ gbs book other $\mathrm{v}$ ersions_r\&cad $=4 \# \mathrm{v}=$ onepage $\& \mathrm{q} \& \mathrm{f}=$ fal se

Waluyo, B. (2000). Pidana dan Pemidanaan. Jakarta: Sinar Grafika. Retrieved from https://opac.perpusnas.go.id/

DetailOpac.aspx?id=203735 